\title{
Effects of medication knowledge on medication adherence among hypertensive patients at Matero level one hospital, Lusaka City, Zambia: A cross sectional study
}

Martin Kampamba ( $\nabla$ martin.kampamba@unza.zm )

University of Zambia

Farhiyyah Abanur

University of Zambia

Christabel Nang'andu Hikaambo

University of Zambia

Steward Mudenda

University of Zambia

Kennedy Saini

University of Zambia

Patrick Kaonga

University of Zambia

\section{Research Article}

Keywords: medication adherence, knowledge, medications, hypertensive patients, hypertension

Posted Date: May 13th, 2021

DOI: https://doi.org/10.21203/rs.3.rs-478010/v1

License: (c) (i) This work is licensed under a Creative Commons Attribution 4.0 International License.

Read Full License 


\section{Abstract}

Background: Medication adherence is the mainstay to good treatment outcomes. Failure to adhere to medication in hypertensive patients may lead to considerable deterioration of the disease resulting in increased costs of healthcare and mortality. Knowledge about the name of the drug, indications and side effects may enhance medication adherence. Therefore, the aim of this study was to assess effects of medication knowledge on medication adherence among hypertensive patients.

Methods: This was a cross-sectional study that involved 120 hypertensive patients. A structured questionnaire was used to collect data on demographic characteristics. Adherence was assessed using the 8-item Morisky Medication Adherence Scale while patient's medication knowledge was assessed using a 7-item scale. Multiple logistic regression was used to assess factors associated with medication adherence.

Results: The mean age of participants was 59 years (SD \pm 14.9$)$ and $10(8.3 \%), 42(35 \%)$ and 68(56.7\%) had adequate, average and poor medication knowledge respectively. The prevalence of adherence in this study was $37.5 \%$. In multivariable logistic regression analysis, uncontrolled blood pressure (BP) (AOR: $0.38, \mathrm{Cl}: 0.16-0.90)$ was associated with lower likelihood of adhering to medication.

Conclusion: The adherence level to treatment was low and medication knowledge of hypertensive patients was generally poor. Uncontrolled BP was associated with non-adherence. Patients with uncontrolled hypertension should be given health education and counselling regarding their condition to improve medication adherence.

\section{Background}

Medication adherence is the mainstay to good treatment outcome while poor adherence to medication has been established as a cornerstone contributor to morbidity and mortality in hypertensive patients[1, 2].Medication adherence is defined as: "the degree to which the person's behaviour matches with the agreed recommendations from a health care provider[3]. Studies has shown that the prevalence of high blood pressure is on the rise especially in sub-Saharan Africa despite the availability of various effective class of antihypertensive medications, uncontrolled BP has kept on surging worldwide[2].

The proportion of adherence is usually high among patients with acute ailments compared to patients with chronic conditions [4]. Hypertension (HTN) mostly turns out to be chronic in the majority and hence calls for a lengthy or lifetime period of treatment with maximum adherence $[5,6]$. There are many factors which lead to poor patient adherence to their prescribed medications. One study reported that a significantly higher proportion of the group that was adherent named their drugs correctly and could also mention indication, dosage, timing, and duration of its use[6]. Furthermore, issues like not having somebody to help keep track of when to take medications, having the urge to take medication only when in discomfort and fear of side effects such as dizziness and headache have also been recorded as drivers to poor adherence to antihypertensive medications [7]. 
Medication knowledge has also been found to be a determinant of medication adherence in hypertensive patients. The ability to remember the names of drugs, it's timing, the correct dose and indications have been shown to be associated with non- adherence [6], also, some have reported that knowledge about HTN and its treatment influence adherence [8] .

While the knowledge of hypertension as a condition and its effect on medication adherence has been well investigated, effects of the knowledge of antihypertensive medication on the adherence to medication have not been extensively studied. Therefore, this study aimed at assessing the effects of medication knowledge on the medication adherence among hypertensive patients at Matero Level 1 Hospital, Lusaka, Zambia.

\section{Methods}

\section{Study setting}

This was a cross-sectional study carried out in Lusaka City at outpatients' department at Matero level 1 hospital, in Lusaka Zambia. The study was conducted from February to March 2018. The hospital attends to an estimated 300 hypertensive patients per month and is a referral for patients from clinics and health centres in its vicinity.

\section{Inclusion and exclusion criteria}

The study included hypertensive patients of age 18 years and above receiving antihypertensive treatment for at least 6 months. We excluded patients that were mentally retarded and those who did not sign informed consent form.

\section{Sample size}

Using the single population proportion formula $[n=\quad(1-P) /], n=S a m p l e ~ s i z e, ~ Z=1.96$, factor from normal distribution. $\mathrm{P}=$ prevalence is 0.094 (based on hypertension prevalence in a study done by (Doulougou et al., 2014)[9] d=Absolute sampling error. The sample size was calculated to be 130 .

\section{Data collection}

At the beginning of the study, the participants were informed about the objective of the study and that their participation was voluntary. Confidentiality was assured by using codes rather than names. Data collection about medication knowledge was done using a pretested self-administered questionnaire which was a standard questionnaire adopted from the previous study[6] and modified to suit our setting.

The questionnaire contained closed ended questions and was divided into three sections; Section A aimed at obtaining demographic information about the participants including age, sex, marital status, occupation, residence and education level. Section B focused on getting information on the hypertensive medication knowledge and a score of 1 was given for each correct answer and otherwise zero score was 
given. For the purpose of this study, medication knowledge consisted of seven specific items of information which included medication name, purpose, side effects, duration of therapy, goals of therapy, expiry date and dose. A score of 0-7 was used. A score of 0-3 was considered as poor knowledge, a score of 4-5 moderate knowledge and a high score of 6-7 adequate knowledge. In order to assess the association between knowledge and patients' medication adherence, participants were clustered into those who had adequate knowledge and those who had poor knowledge.

Section $\mathrm{C}$ was designed to obtain information about the patients' medication adherence. The (Morisky Medication Adherence Scale), an 8-score scale containing 8 questions was used to obtain this information. Each incorrect response was given a score of 1 . A score of 0 meant that the patient was adherent and a score of 1-8 meant that the patient was non-adherent. Blood pressure control was classified based on Eighth Joint National Committee(JNC 8)[10].Systolic blood pressure of $<140$ and diastolic of $<90 \mathrm{mmHg}$ showed good blood pressure control in patients less than 60 years old while systolic blood pressure of $\geq 140$ and diastolic of $\geq 90 \mathrm{mmHg}$ showed poor blood pressure control in patients less than 60 years old. Systolic blood pressure of $<150$ and diastolic of $<90 \mathrm{mmHg}$ showed good blood pressure control in patients aged 60 years and above while ssystolic blood pressure of $\geq 150$ and diastolic of $\geq 90 \mathrm{mmHg}$ showed poor blood pressure control in patients aged 60 years and above.

\section{Data analysis}

Data was first cleaned up and checked for accuracy and consistency then entered and analysed using STATA version 13 (Stata Corp., College Station, Texas, USA). Frequencies, proportions and summary statistics were used to describe the study population in relation to relevant variables. Unadjusted regression was carried out to see the putative associations of each independent variable with the dependent variable. Independent variables with $p$-value $<0.2$ in the unadjusted logistic regression were transferred into the adjusted logistic regression model and variables with P-value $<0.05$ in the final model were regarded as associated factors of medication adherence. Odds ratio and $95 \%$ confidence interval were also used to identify the presence and strength of association.

\section{Results}

\section{Socio-demographic characteristics}

In this study, a total of 130 questionnaires were circulated, of which 120 were filled resulting in a response rate of $92.3 \%$. The mean age of the participants was 59 years (SD \pm 14.9$)$, with above half $62(51.7 \%)$ being over 60 years old. Under three-quarters $86(71.7 \%)$ of the participants were female and majority 66 $(55 \%)$ of the participants were single. Most participants 75 (62.5\%) were unemployed, half were leaving in high density populated areas and $84(70 \%)$ had uncontrolled high BP. The socio-demographic characteristics of the 110 participants in the study are presented in Table 1.

Table 1. Baseline characteristics of hypertensive patients $(N=120)$ 


\begin{tabular}{|c|c|c|}
\hline Variable & Frequency & Percentage \\
\hline $\begin{array}{l}\text { Age } \\
\quad<60 \text { years } \\
\geq 60 \text { years }\end{array}$ & $\begin{array}{l}58 \\
62\end{array}$ & $\begin{array}{l}48.3 \\
51.7\end{array}$ \\
\hline $\begin{array}{l}\text { Sex } \\
\quad \text { Male } \\
\text { Female }\end{array}$ & $\begin{array}{l}34 \\
86\end{array}$ & $\begin{array}{l}28.3 \\
71.7\end{array}$ \\
\hline $\begin{array}{l}\text { Education Level } \\
\text { Primary } \\
\text { Secondary } \\
\text { Tertiary }\end{array}$ & $\begin{array}{l}72 \\
38 \\
10\end{array}$ & $\begin{array}{r}60.0 \\
31.7 \\
8.3\end{array}$ \\
\hline $\begin{array}{l}\text { Marital status } \\
\text { Single } \\
\text { Married }\end{array}$ & $\begin{array}{l}66 \\
54\end{array}$ & $\begin{array}{l}55.0 \\
45.0\end{array}$ \\
\hline $\begin{array}{l}\text { Employment Status } \\
\text { Employed } \\
\text { Unemployed }\end{array}$ & $\begin{array}{l}45 \\
75\end{array}$ & $\begin{array}{l}37.5 \\
62.5\end{array}$ \\
\hline $\begin{array}{l}\text { Residence } \\
\text { Medium density } \\
\text { High density } \\
\end{array}$ & $\begin{array}{l}60 \\
60 \\
\end{array}$ & $\begin{array}{l}50 \\
50 \\
\end{array}$ \\
\hline $\begin{array}{l}\text { Treatment outcome } \\
\text { Controlled BP } \\
\text { Uncontrolled BP }\end{array}$ & $\begin{array}{c}36 \\
84\end{array}$ & $\begin{array}{l}30 \\
70\end{array}$ \\
\hline
\end{tabular}

\section{Patient's knowledge about their medications}

In this study regarding the medication knowledge as shown in Table-2, most participants were aware about the purpose of medication 100 (83.3\%), expiry date 105 (87.5\%) and duration of treatment 73 $(60.8 \%)$. Low medication knowledge awareness was observed regarding the name of medication 51 $(42.5 \%)$ dose $15(12.5 \%)$, goal of therapy $9(6.7 \%)$ and side effects 8 (6.7\%). Overall, the percentage of medication knowledge in this study was as poor, moderate and adequate were 68 (56.7\%), $42(35 \%)$ and $10(8.3 \%)$ respectively.

Table 2: Patient's knowledge about their medications

\begin{tabular}{|l|l|l|}
\hline Knowledge item & Frequency & Percentage \\
\hline knows name of medication & 51 & 42.5 \\
\hline Knows purpose of medication & 100 & 83.3 \\
\hline Knows dose of medication & 15 & 12.5 \\
\hline Knows duration of medication & 73 & 60.8 \\
\hline Knows goals of therapy & 9 & 6.7 \\
\hline Knows expiry date & 105 & 87.5 \\
\hline Knows Side effects & 8 & 6.7 \\
\hline Total knowledge & & \\
\hline Poor & 68 & 56.7 \\
\hline Moderate & 42 & 35 \\
\hline Adequate & 10 & 8.3 \\
\hline
\end{tabular}




\section{Factors associated with medication adherence}

Based on unadjusted analysis, uncontrolled high BP (COR: 0.44, Cl: 0.20-0 .98) and poor level of medication knowledge (COR: 0.23 , Cl: 0.06-0.93) were associated with lower likelihood of medication adherence while knowing the goal of therapy (COR: 6.72, Cl: 1.33 -33.9) showed higher likelihood of medication adherence (Table 3 ). After transferring the variables into the adjusted regression analysis, uncontrolled high BP (AOR: 0.38, Cl: 0.16-0.90) was the only factor that significantly associated with lower likelihood of medication adherence as shown in Table 4.

Table 3. Bivariate analysis of factors associated with medication adherence

\begin{tabular}{|c|c|c|c|c|}
\hline Variable & Category & COR & $95 \% \mathrm{CI}$ & P. value \\
\hline \multirow[t]{2}{*}{ Age } & $<60$ years old & Ref & & \\
\hline & $\geq 60$ years old & 0.89 & $0.43,1.88$ & 0.777 \\
\hline \multirow[t]{2}{*}{ Gender } & Male & Ref & & \\
\hline & Female & 0.73 & $0.32,1.69$ & 0.465 \\
\hline \multirow[t]{2}{*}{ Marital Status } & Single & & & \\
\hline & Married & & $0.33,1.48$ & 0.359 \\
\hline \multirow[t]{3}{*}{ Education Level } & Primary & Ref & & \\
\hline & Secondary & 1.46 & $0.64,3.35$ & 0.371 \\
\hline & Tertiary & 1.01 & $0.26,3.90$ & 0.987 \\
\hline \multirow[t]{2}{*}{ Employment Status } & Employed & Ref & & \\
\hline & Unemployed & 1.01 & $0.48,2.18$ & 0.961 \\
\hline \multirow[t]{2}{*}{ Residence } & Medium Density & Ref & & \\
\hline & High Density & 0.52 & $0.25,1.10$ & 0.091 \\
\hline \multirow[t]{2}{*}{ Treatment outcome } & Controlled BP & Ref & & \\
\hline & Uncontrolled BP & 0.44 & $0.20 \quad 0.98$ & $0.045^{*}$ \\
\hline \multirow[t]{2}{*}{ Knows medication name } & Yes & Ref & & \\
\hline & No & 0.98 & $0.46,2.07$ & 0.962 \\
\hline \multirow[t]{2}{*}{ Knows medication purpose } & Yes & Ref & & \\
\hline & No & 0.54 & $0.20,1.42$ & 0.210 \\
\hline \multirow[t]{2}{*}{ Knows medication dose } & Yes & Ref & & \\
\hline & No & 2.10 & $0.71,6.25$ & 0.182 \\
\hline \multirow[t]{2}{*}{ Knows medication duration } & Yes & Ref & & \\
\hline & No & 0.61 & $0.29,1.29$ & 0.194 \\
\hline \multirow[t]{2}{*}{ Knows goal of therapy } & No & Ref & & \\
\hline & Yes & 6.72 & $1.33,33.9$ & 0.021* \\
\hline \multirow[t]{2}{*}{ Knows Side effects } & Yes & Ref & & \\
\hline & No & 1.73 & $0.41,7.30$ & 0.454 \\
\hline \multirow[t]{2}{*}{ Knows expiry date } & Yes & Ref & & \\
\hline & No & 0.65 & $0.23,1.93$ & 0.435 \\
\hline \multirow[t]{2}{*}{ Medication knowledge } & good & Ref & & \\
\hline & poor & 0.23 & $0.06,0.93$ & 0.039* \\
\hline
\end{tabular}

COR: Crude old ratio, CI: Confidence interval, Ref: Reference category, * P-value $<0.05$ 
Table 4: Multivariable logistic regression to determine factors associated with medication adherence

\begin{tabular}{|c|c|c|c|c|}
\hline Variable & Category & AOR & $95 \% \mathrm{CI}$ & P. value \\
\hline \multirow[t]{2}{*}{ Residence } & Medium Density & REF & & \\
\hline & High Density & 0.53 & $0.21,1.97$ & 0.177 \\
\hline \multirow[t]{2}{*}{ Treatment outcome } & Controlled BP & Ref & & \\
\hline & Uncontrolled BP & 0.38 & $0.16,0.90$ & $0.029 *$ \\
\hline \multirow[t]{2}{*}{ Knows medication purpose } & Yes & Ref & & \\
\hline & No & 0.64 & $0.21,1.97$ & 0.440 \\
\hline \multirow[t]{2}{*}{ Knows medication dose } & Yes & Ref & & \\
\hline & No & 1.67 & $0.38,7.47$ & 0.499 \\
\hline \multirow[t]{2}{*}{ Knows medication duration } & Yes & Ref & & \\
\hline & No & 0.76 & $0.29,1.94$ & 0.563 \\
\hline \multirow[t]{2}{*}{ Knows goal of therapy } & No & Ref & & \\
\hline & Yes & 5.02 & $0.86,29.3$ & 0.073 \\
\hline \multirow[t]{2}{*}{ Level of knowledge } & good & Ref & & \\
\hline & poor & 0.39 & $0.06,2.47$ & 0.317 \\
\hline
\end{tabular}

AOR: Adjusted old ratio, CI: Confidence interval, Ref: Reference category, * P-value $<0.05$

\section{Discussion}

We assessed the effects of medication knowledge on medication adherence in hypertensive patients at Matero level-1 hospital, in Lusaka City Zambia. We found that hypertensive patients had low level of medication adherence and poor knowledge about antihypertensive drugs. Uncontrolled high blood pressure (BP) was found to be significantly associated with adherence to medication.

The effectiveness to treatment is lowered due to non-adherence to medication and places a significant cost burden on healthcare systems[11, 12].Therefore, non-adherence to medication is a problem in the management of patients with long-lasting diseases such hypertension requiring long-term treatments $[13$, 14].

In this study, only $37.5 \%$ of patients adhered to their antihypertensive medications. The proportion of adherence to antihypertensive medications in this study was lower than those reported in Pakistan $62.5 \%$ [15],Ghana 41.4\% [16], Egypt 73.2\%[6] , Ethiopia 67\% [14], 65.1\% China[17] and England 79\% [18].The lower level of adherence in our study could be probably attributed to low level of education and old age among the participants as more than half had only attained primary level and above 60 years. Some studies have reported that insufficient patient education influenced medication compliance especially in older patients [19]. However, contrary to this study, other studies have reported much lower levels of adherence. For example, in France 33.6\%[20], Ethiopia 31.4\%[21],China 27.5\%[22] and Cameroon 32.3\% [23]. Although we cannot offer a plausible explanation for such a finding, it is surprising that France and 
China which are developed countries and expected to have more educated people had lower levels compared to this study.

This study reviewed that most of the participants had good medication knowledge about the purpose of medication but had poor medication knowledge regarding side effects. This is supported by three previous studies that were conducted in Denmark, USA and Jordan which also reported similar findings [24-26]. Additionally, our study observed that less than half (42.5\%) of the participants correctly named their medication. This is conflicting to the finding of a previous study which reported more than half $(69.5 \%)$ of respondent named their medications correctly[6].The difference in study findings regarding correctly naming the medication could be attributed to the age because the majority of the participants in our study were elderly patients who could easily forget the name of the medicines. Additionally, level of education could have contributed as the majority of participants in our study had attained only primary education.

Generally, our study found that only $8 \%$ of the participants had adequate medication knowledge. The medication knowledge score in this study was very poor when compared to medication knowledge reported in Jordan (62.3\%) [26] and Turkey (64.5\%)[27].The high medication knowledge levels observed in the previous two studies done in Jordan and Turkey could be ascribed to high literate levels of participants as most of them had attained high education as well as relatively young age. High literate levels as well as relatively young age have been reported in some studies to significantly predict the medication knowledge [26-28].

Our study also assessed the independent valuables associated with medication adherence. In the adjusted logistic regression analysis, Individuals with uncontrolled high BP were significantly more likely to have lower medication adherence. This finding is in keeping with other studies [8, 29].In this study, the age, education level and gender were not associated with medication adherence. This is in contrast with some studies which reported that individuals with younger age $[8,30]$, high education level $[26,31]$ and male patients [6] are more likely to adhere to medication. However, some studies have reported that advanced age [13,32] and female patients [28] are more likely to adhere to medication .

This study found no association between medication knowledge and medication adherence. In disagreement to this study, some studies have found increased medication knowledge to be associated with medication adherence[26, 28]. Regarding the contents of medication knowledge, a study that was conducted in Turkey reported that patients who knew the names, the purpose and side effects of their medications were likely to adhere to treatment [27]. Also, Karaeren et al. (2009) reported that knowing the duration and the purpose of medicine significantly increased the adherence rates while knowing the side effects of medicine reduced the adherence to medication [33] . The findings of the above studies regarding the contents of medication knowledge does not support the findings of the present study in which we found no association between contents of medication knowledge and medication adherence.

The nature of our study may have encountered several study limitations. The inherent nature of the cross-sectional studies are prone to social desirability bias[34]. However, we assured the participants that 
their responses were not going to be tied to them and the questionnaire was self-administered. The nature of our study may also be predisposed to recall bias and subsequently affect true adherent level[35] . Nevertheless, we adopted the widely accepted Morisky Medication Adherence Scale of measuring adherence which contains carefully selected questions.

\section{Conclusion}

The adherence level to treatment was low and medication knowledge of hypertensive patients was generally very poor. In this study, uncontrolled BP was associated with non-adherence. Patients with uncontrolled hypertension should be given health education and counselling regarding their condition to improve medication adherence.

\section{Declarations}

\section{Acknowledgement}

Our heartfelt gratitude goes to the University of Zambia, School of Health Sciences and Pharmacy department for the support rendered during the research period. We would also like to thank members of staff at Matero Level 1 hospital for their technical support during data collection.

\section{Authors' contributions}

M.K, the primary author, was involved in design of the study, conducted the research, performed the data analysis and interpretation, and drafted the manuscript. K.S. assisted in data analysis and drafting the manuscript and provided critical edits to the manuscript. S.M. was involved with study conception, study oversight, and provided critical edits to the manuscript. C.N.H. was involved in data interpretation and provided critical edits to the

manuscript. P.K. assisted in data analyses and interpretation of the data. F.A was involved in the conception and design of the study as well as data acquisition. The final version of the manuscript has been approved by all authors.

\section{Funding}

This research did not receive any funding from sponsoring agencies in the public, commercial, or not-for-profit sectors.

\section{Availability of data and materials}

Not applicable

\section{Ethics approval and consent to participate}

Ethical approval was sought from the University of Zambia Research Ethics Committee (UNZABREC) approval number 20171226142. Written permission to conduct the study was obtained from the District Health Office of Lusaka and Matero level 1 hospital management where the study was conducted. The 
nature and objectives of the study were explained to the patients who agreed to participate and written informed consent was formally obtained. The patients were not subjected to any kind of risks at any point during the study and were allowed to withdraw from the study at any point during the study which did not affect the quality of health care services they received. All the methods used in this study were performed in accordance with the relevant guidelines and regulations.

\section{Consent for publication}

Not applicable

\section{Competing interests}

The authors affirm declare that they have no competing interests.

\section{References}

1. Mackenzie, I.S., \& MacDonald, T. M., Identifying poor adherence to antihypertensive medications in patients with resistant hypertension.Br J Clin Pharmacol. 2019;85(1):5-

7.https://doi.org/10.1111/bcp.13806.

2. Macquart de Terline D, K.A., Kramoh KE, Ali Toure I, Mipinda JB, Diop IB, Nhavoto C, Balde DM, Ferreira B, Dèdonougbo Houenassi M, Ikama MS., Factors associated with poor adherence to medication among hypertensive patients in twelve low and middle income Sub-Saharan countries. PloS one 14, no. 7 (2019):e0219266.https://doi:10.1371/journal.pone.0219266.

3. Sabaté, E., Adherence to long-term therapies: evidence for action. World Health Organization; 2003.

4. Jimmy, B., \& Jose, J, Patient medication adherence: measures in daily practice. Oman medical journal. 2011 May;26(3):155. 155-9.https://doi:10.5001/omj.2011.38.

5. Jackevicius CA, M.M., Tu JV., Adherence with statin therapy in elderly patients with and without acute coronary syndromes. Jama. 2002 Jul 24;288(4):462-7.https://doi:10.1001/jama.288.4.462.

6. Salama AA, Y.A., Elbarbary W. , Medication knowledge as a determinant of medication adherence in geriatric patients, Serse Elian City, Menoufia Governorate, Egypt. Menoufia Medical Journal. 2017 Jan 1;30(1):63.https://doi:10.4103/1110-2098.211476.

7. Mamaghani EA, H.E., Maghsoodi E, Soleimani F., Barriers to Medication Adherence among Hypertensive Patients in Deprived Rural Areas. Ethiopian journal of health sciences. 2020 Jan 1;30(1).https://doi:10.4314/ejhs.v30i1.11.

8. Getenet A, T.M., Ferede A, Molla Y. , Determinants of adherence to anti-hypertensive medications among adult hypertensive patients on follow-up in Hawassa Referral Hospital: A case-control study. JRSM cardiovascular disease. 2019 Dec;8:2048004019892758.https://doi:10.1177/2048004019892758.

9. Doulougou B, K.S., Rossier C, Soura A, Zunzunegui MV. , Differences in hypertension between informal and formal areas of Ouagadougou, a sub-Saharan African city. BMC public health. 2014 
Dec;14(1):1-9.https://doi:10.1186/1471-2458-14-893.

10. James PA, O.S., Carter BL, Cushman WC, Dennison-Himmelfarb C, Handler J, Lackland DT, LeFevre ML, MacKenzie TD, Ogedegbe O, Smith SC., 2014 evidence-based guideline for the management of high blood pressure in adults: report from the panel members appointed to the Eighth Joint National Committee (JNC 8). Jama. 2014 Feb 5;311(5):507-20.https://doi:10.1001/jama.2013.284427.

11. Cutler RL, F.-L.F., Frommer M, Benrimoj C, Garcia-Cardenas V. , Economic impact of medication nonadherence by disease groups: a systematic review. BMJ open. 2018 Jan 1;8(1):e016982.https://doi:10.1136/bmjopen-2017-016982.

12. Khera R, V.-E.J., Das SR, Virani SS, Kash BA, De Lemos JA, Krumholz HM, Nasir K. , Cost-related medication nonadherence in adults with atherosclerotic cardiovascular disease in the United States, 2013 to 2017. Circulation. 2019 Dec17;140(25):2067-

75.https://doi.org/10.1161/CIRCULATIONAHA.119.041974.

13. Fernandez-Lazaro Cl, G.-G.J., Adams DP, Fernandez-Lazaro D, Mielgo-Ayuso J, Caballero-Garcia A, Racionero FM, Córdova A, Miron-Canelo JA. , Adherence to treatment and related factors among patients with chronic conditions in primary care: a cross-sectional study. BMC family practice. 2019 Dec;20(1):1-2.https://doi:10.1186/s12875-019-1019-3.

14. Hameed MA, D.I., Medication adherence and treatment-resistant hypertension: a review. Drugs in context.2019;8.https://doi:10.7573/dic.212560.

15. Khan MN, S.N., Ashraf T, Naseeb K, Kumar R, Bhatti U, Ali ST, Karim M. , Perceptions and practices towards medication non-adherence among hypertensive patients: An observational study. Cureus. 2019 Oct;11(10).https://doi:10.7759/cureus.5917.

16. Obirikorang Y, O.C., Acheampong E, Odame Anto E, Gyamfi D, Philip Segbefia S, Opoku Boateng M, Pascal Dapilla D, Brenya PK, Amankwaa B, Adu EA. , Predictors of noncompliance to antihypertensive therapy among hypertensive patients Ghana: application of health belief model.International journal of hypertension. 2018 Jun19;2018.https://doi.org/10.1155/2018/4701097.

17. Lee, G.K., Wang, H.H., Liu, K.Q., Cheung, Y., Morisky, D.E. and Wong, M.C., 2013. , Determinants of medication adherence to antihypertensive medications among a Chinese population using Morisky Medication Adherence Scale. PloS one, 8(4), p.e62775.https://doi:10.1371/journal.pone.0062775.

18. Khan MU, S.S., Hameed T. , Barriers to and determinants of medication adherence among hypertensive patients attended National Health Service Hospital, Sunderland. Journal of pharmacy \& bioallied sciences. 2014 Apr;6(2):104.https://doi:10.4103/0975-7406.129175.

19. Vermeire E, H.H., Van Royen P, Denekens J. Patient. , adherence to treatment: three decades of research. A comprehensive review. Journal of clinical pharmacy and therapeutics. 2001 Oct 30;26(5):331-42.https://doi:10.1046/j.1365-2710.2001.00363.x.

20. Vallée A, G.A., Grave C, Sorbets E, Blacher J, Olié V. , Patterns of hypertension management in France in 2015: The ESTEBAN survey. The Journal of Clinical Hypertension. 2020 Apr;22(4):66372.https://doi:10.1111/jch.13834. 
21. Berisa HD, D.M., Non-adherence related factors to antihypertensive medications among hypertensive patients on follow up at Nedjo General Hospital in West Ethiopia. The Open Public Health Journal. 2018 Feb 28;11(1).https://doi:10.2174/1874944501811010062.

22. Pan J, W.L., Wang H, Lei T, Hu B, Xue X, Li Q. , Determinants of hypertension treatment adherence among a Chinese population using the therapeutic adherence scale for hypertensive patients. Medicine. 2019 Jul;98(27).https://doi:10.1097/MD.0000000000016116.

23. Adidja NM, A.V., Aminde JA, Ngwasiri CA, Ngu KB, Aminde LN. , Non-adherence to antihypertensive pharmacotherapy in Buea, Cameroon: a cross-sectional community-based study. BMC Cardiovascular disorders. 2018 Dec;18(1):1-9.https://doi.org/10.1186/s12872-018-0888-z.

24. Barat I, A.F., Damsgaard EM. , Drug therapy in the elderly: what doctors believe and patients actually do. British journal of clinical pharmacology. 2001 Jun;51(6):615-22.https://doi:10.1046/j.03065251.2001.01401.x.

25. Marks JR, S.J., Groninger H, Plews-Ogan ML. , The association of health literacy and sociodemographic factors with medication knowledge. Patient education and counseling. 2010 Mar 1;78(3):372-6.https://doi:10.4103/1817-1737.109823.

26. Awwad O, A.A., Al-Muhaissen S, Morisky D., The influence of patients' knowledge on adherence to their chronic medications: a cross-sectional study in Jordan. International journal of clinical pharmacy. 2015 Jun 1;37(3):504-10.https://doi:10.1007/s11096-015-0086-3.

27. Okuyan B, S.M., Izzettin FV. , Assessment of medication knowledge and adherence among patients under oral chronic medication treatment in community pharmacy settings. Pharmacoepidemiology and drug safety.2013 Feb;22(2):209-14.https://doi:10.1002/pds.3275.

28. Mekonnen GB, G.D., Low medication knowledge and adherence to oral chronic medications among patients attending community pharmacies: a cross-sectional study in a low-income country. BioMed Research International. 2020 Jan 11;2020. https://doi.org/10.1155/2020/4392058.

29. Akoko BM, F.P., Ngu RC, Ngu KB. , Knowledge of hypertension and compliance with therapy among hypertensive patients in the Bamenda Health District of Cameroon: a cross-sectional study. Cardiology and therapy. 2017 Jun;6(1):53-67.https://doi:10.1007/s40119-016-0079-x.

30. Goh BQ, T.A., Khoo RS, Goh BK, Lo PF, Lim CJ. , Effectiveness of medication review in improving medication knowledge and adherence in primary care patients. Proceedings of Singapore Healthcare. 2014 Jun;23(2):134-41.https://doi:10.1177/201010581402300207.

31. Bochkareva EV, B.E., Kim IV, Kontsevaya AV, Drapkina OM, Leon D, McKee M. , Adherence to antihypertensive medication in Russia: a scoping review of studies on levels, determinants and intervention strategies published between 2000 and 2017. Archives of Public Health. 2019 Dec;77(1):1-6.https://doi:10.1186/s13690-019-0366-9.

32. Shani M, L.A., Vinker S. , Adherence to oral antihypertensive medications, are all medications equal? The Journal of Clinical Hypertension. 2019 Feb;21(2):243-8.https://doi:10.1111/jch.13475.

33. Karaeren H, Y.M., Uzun Ş, Baysan O, Köz C, Kara B, Kırılmaz A, Naharcı İ, Pınar M, Yılmaz MB, Uzun M., The effect of the content of the knowledge on adherence to medication in hypertensive patients. 
Anatolian Journal of Cardiology/Anadolu Kardiyoloji Dergisi. 2009 Jun 1;9(3).

34. Larson, RB. Controlling social desirability bias. International Journal of Market Research. 2019 Sep;61(5):534-47.https://doi.org/10.1177/1470785318805305.

35. Althubaiti, A.Information bias in health research: definition, pitfalls, and adjustment methods. Journal of multidisciplinary healthcare.2016;9:211.https://doi:10.2147/jmdh.s104807 